\title{
Efficacy of Organic and Conventional Fungicides and Impact of Application Timing on Control of Tomato Late Blight Caused by US-22, US-23, and US-24 Isolates of Phytophthora infestans
}

\author{
Anna C. Seidl Johnson, Stephen A. Jordan, and Amanda J. Gevens, Department of Plant Pathology, University of Wisconsin-Madison, \\ Madison 53706
}

\begin{abstract}
Seidl Johnson, A. C., Jordan, S. A., and Gevens, A. J. 2015. Efficacy of organic and conventional fungicides and impact of application timing on control of tomato late blight caused by US-22, US-23, and US-24 isolates of Phytophthora infestans. Plant Dis. 99:641-647.

Late blight, caused by Phytophthora infestans, is one of the most economically important diseases of potato and tomato worldwide. Repeated preventative application of fungicides is the primary means of control on susceptible solanaceous host crops. For organic production, fungicide choices are limited, and little efficacy data on noncopper options is available on which to base control recommendations. Twelve fungicides, including organic and conventional selections, were evaluated for both preventative and postinfection control of a single infection cycle of late blight caused by isolates representing three recently identified $P$. infestans clonal lineages (US-22, US-23, and US-24) using a detached tomato leaf assay. A subset of the most effective fungicides was also tested for preventative control of a single infection cycle of late blight caused by an isolate of US-23 on potted whole tomato plants under laboratory conditions. Fungicide applications made 2 days after inoculation failed to significantly control late blight on detached leaves in all treatments, with the exception of Bravo Ultrex (US-23 only) and Phostrol (US-22 only). Preventative fungicide applications of Bravo Ultrex, Ridomil Gold SL, Revus, Zonix, and low and high rates of EF400 significantly controlled

late blight caused by US-22, -23 , and -24 isolates. Additionally, preventative application of Phostrol significantly controlled late blight caused by the US-22 isolate; and Phostrol, low rate of Mycostat, and high rate of Champ significantly controlled late blight caused by the US-23 isolate. Late blight caused by the US-24 isolate was significantly reduced compared with US-22 and US-23 isolates for all fungicide treatments applied after inoculation, as well as for all preventative fungicide treatments, with the exception of Bravo, Ridomil, and Revus. In whole-pottedplant assays with the US-23 isolate, late blight was significantly controlled by preventative application of Bravo Ultrex, Ridomil Gold SL, and high rate of EF400; disease was not significantly controlled by Zonix, low rate of EF400, Phostrol, or low and high rates of Champ. Based on these results, it is anticipated that currently available fungicides with suitability to conventional and organic systems can effectively control late blight caused by new clonal lineages of $P$. infestans when applied preventatively and that late blight caused by the US-24 clonal lineage may require less fungicide use than US-22 or US-23 to mitigate disease.
\end{abstract}

Phytophthora infestans (Mont.) de Bary causes late blight, one of the most important diseases of potato (Solanum tuberosum L.) and tomato (S. lycopersicum L.) production worldwide. In the United States, it is estimated that $\$ 77.1$ million per year is spent on fungicides to control potato late blight (34). In spite of this, losses can still be high and late blight has been estimated to cost growers $\$ 507$ per hectare per year, or $\$ 287.8$ million annually, as a result of both fungicide costs and crop losses (34). Worldwide, the disease has been estimated to cost growers $\$ 6.7$ billion annually, in both fungicide costs and crop losses (36).

The biology of $P$. infestans in the United States influences management of late blight. $P$. infestans is a heterothallic oomycete that reproduces asexually in the United States $(5,7,18,22)$. The A1 and A2 mating types historically have not been in proximity and the possibility for sexual reproduction of resilient oospores has not been widely documented $(12,38,52)$. As such, the pathogen requires living plant material to survive, limiting survival in northern winters, and genetic variation within the population is low $(11,22,25,55)$. Reproduction is primarily via asexual sporangia. These short-lived reproductive structures are produced in large numbers on lesions and are easily wind blown to rapidly spread the pathogen to surrounding plants and other fields, often quickly devastating an unprotected, susceptible crop (65). The asexual descendants of a single genotype are referred to as a clonal lineage $(21,24)$, a designation that can be

Corresponding author: A. J. Gevens; E-mail: gevens@wisc.edu

Accepted for publication 26 September 2014.

http://dx.doi.org/10.1094/PDIS-04-14-0427-RE

(C) 2015 The American Phytopathological Society associated with several genotypic characteristics such as the RG57 restriction fragment length polymorphism fingerprint (26) and allozyme fingerprint (27), and several practical phenotypic characteristics important for management such as mating type and sensitivity to the fungicide active ingredient mefenoxam $(12,41,55,59)$. Several clonal lineages of $P$. infestans have been discovered during the past 30 years in the United States (28). Some have been limited in distribution, found only in limited geographic regions or for single seasons $(28,32,41)$, but others, such as the US-1 and US-8, and US-22, US-23, and US-24 clonal lineages in recent years (2009 to 2013), have been widespread spatially and temporally $(11,25,28,55)$. New lineages have quickly displaced previously predominant lineages $(28,29,42,55)$, making it important to continue to study new lineages of $P$. infestans to optimize management.

Several integrated control strategies are employed to manage late blight. In northern regions where freezing temperatures prevail in the winter months, living plant material containing $P$. infestans is typically destroyed by frost. However, infected potato tubers could be protected from freezing in cull piles (5) or buried in production fields after harvest. Therefore, it is important to destroy cull piles and manage volunteers (plants that emerge from unharvested potato tubers from a previous production season) to eliminate these potential inoculum sources for the next crop. Planting late-blight-free seed tubers is critical to minimize initial inoculum $(39,65)$. Genetic resistance has been deployed in both potato $(30,47,60,66)$ and tomato $(2,43,50)$, contributing to an overall integrated management plan (63). However, $P$. infestans has historically demonstrated an exceptional ability to overcome plant resistance, sometimes carrying genes to overcome host resistance genes that have not yet been deployed $(21,30)$. Consequently, complete reliance on genetic resistance for late blight control has been impossible. Therefore, fungicides remain the primary tool to prevent and reduce yield loss from late blight $(23,64)$. 
Disease forecasting systems which apply knowledge of pathogen biology, temperature, and humidity to predict the likelihood of risk have been developed to optimize timing of fungicide applications and are often used in management of late blight $(44,64)$. Many available fungicides are protectants and must be applied before disease onset to be effective (6). Other groups of fungicides include antisporulants, which can further reduce late blight spread from an infected field; translaminar fungicides, which have limited ability to halt established infections in a curative manner; and truly systemic fungicides such as the active ingredient mefenoxam (6,8,23). Mefenoxam can reportedly limit established infections, provided the disease-causing clonal lineage is sensitive (9). Several clonal lineages such as US- 8 and US-24 are completely insensitive to mefenoxam, rendering this fungicide ineffective; US-22 and US-23 are sensitive to mefenoxam $(11,13,28,32,33,40,48)$. Mefenoxam resistance has become one of the standard phenotypes determined for $P$. infestans isolates that are maintained for study $(11,55)$.

In organic potato and tomato production systems, fungicides are often necessary to control late blight, just as in conventional systems. Many years of research have established that formulations containing copper are the most effective organic-approved fungicide options $(15,61,62)$. However, there are concerns over the extensive use of copper in organic production. Copper kills a broad range of microorganisms and, with repeated applications, there is concern that copper could accumulate in soil, with potential detrimental effects on soil microorganisms $(4,14,19)$. Copper residues on plant tissues can cause dermatitis when coming in contact with human skin (53); therefore, field workers may need appropriate personal protective equipment when working in recently treated fields. Visible residues on harvested fruit may be undesirable to consumers. Some noncoppercontaining fungicides have been developed for use in organic systems but the efficacy of these products is often limited or poorly characterized in third-party research (15).

With new clonal lineages of $P$. infestans displacing the US- 8 clonal lineage in recent years, and a growing interest in the development of organic-approved fungicides as the market for organic potato and tomato expands (51), testing the efficacy of a broad range of fungicides against new lineages of $P$. infestans is needed. The objectives of our research were to evaluate the efficacy of 12 organic, biorational, and conventional fungicides against individual isolates of the recently identified US-22, US-23, and US-24 clonal lineages of $P$. infestans on susceptible tomato, and to compare the effectiveness of the treatments when applied before versus after pathogen inoculation. We evaluated a subset of the most effective fungicides against the US-23 isolate, which has become the most common of the lineages during 2013 and $2014(1,55)$, on potted tomato plants under controlled conditions. Results will better inform fungicide recommendations for new, prominent clonal lineages of $P$. infestans in organic and conventional systems, leading to increased late blight control.

\section{Materials and Methods}

P. infestans isolates. The US-22 (Pi7-09a), US-23 (Pi16-10a), and US-24 (Pi21-10a) isolates used in this study were collected from symptomatic plant tissues from Wisconsin production fields and gardens and have been previously characterized (55). Pi7-09a (US-22, A2, mefenoxam sensitive) was isolated from infected tomato fruit, Pi16-10a (US-23, A1, mefenoxam sensitive) from infected tomato foliage, and Pi21-10a (US-24, A1, mefenoxam intermediately sensitive) from infected potato foliage. All $P$. infestans cultures were derived from single-zoospore isolations, and oospore production in single-isolate cultures was never observed. Isolates were transferred minimally in culture after isolation to maintain the original characteristics of the isolates $(31,37,68)$. For long-term storage, isolates were maintained in hemp seed (45) in the Potato and Vegetable Pathology Laboratory at the University of Wisconsin-Madison. Single representative isolates of each $P$. infestans clonal lineage were used because previous studies indicated that recently identified lineages showed low variation in biological characteristics $(11,49)$.

Inoculum preparation. Three-week-old actively growing cultures of $P$. infestans on rye A agar $(7)$ at $18^{\circ} \mathrm{C}$ in darkness were flooded with sterile distilled water and brushed gently with a sterile glass rod to dislodge sporangia. The resulting suspension was transferred to a sterile, plastic 50-ml centrifuge tube and the concentration determined using a hemacytometer. The concentration was adjusted to 50,000 sporangia/ml for each experiment by adding sterile distilled water.

Fungicide evaluation on detached leaves. Detached-leaf assays were used to determine efficacy of fungicides applied preventatively (before infection) or after inoculation (46,70). Tomato plants ('Brandywine Red'; Reimer Seeds, Saint Leonard, MD) were grown in a growth chamber at $28^{\circ} \mathrm{C}$ with a $14-\mathrm{h}$ photoperiod for 5 weeks. Fully expanded leaflets were detached using a sharp, sterile razor blade, placed adaxial side up onto a clean tray within a chemical fume hood, and sprayed to runoff with each fungicide treatment. Treated leaflets were then placed directly on a thin layer of water agar in 9-cm-diameter petri plates; lids were put on after the fungicide treatments had dried, which was about $1 \mathrm{~h}$ after application. Two leaflets were placed in each plate, for a total of eight leaflets in four petri plates for each treatment. Fungicide rates per total spray volume of $100 \mathrm{ml}$ were determined as follows. Label rates given in quantity of product per acre were converted to quantity per square feet $(=0.093$ square $\mathrm{m})$, which represented the total area of excised leaflets to be treated per fungicide replication. Label rates given in ppm or per volume of water were converted to equivalent proportions per $100 \mathrm{ml}$ of total spray volume. Fungicide treatments were prepared in $100 \mathrm{ml}$ of tap water directly in the canister of a 1-liter Solo sprayer (Solo, Newport News, VA), according to the specific rates (Table 1). The sprayer was pumped 35 times to establish pressure in the tank and ensure a small droplet size. The canister was agitated thoroughly prior to application of each fungicide to ensure a homogeneous suspension. Three sprayers were dedicated for this trial. Each sprayer was thoroughly cleaned with water-detergent solution and rinsed four times with clean water after each use. Preparation and application of all fungicide treatments was conducted within $30 \mathrm{~min}$ (with the assistance of three applicators) to ensure that the time between fungicide treatment and inoculation was similar for all treatments. One full spray from an atomizer (average $75 \mu \mathrm{l}$ ) containing $P$. infestans at 50,000 sporangia/ml was applied to each leaf within $2 \mathrm{~h}$ of the fungicide application for the preventative experiment. The postinoculation experiment was set up in the manner described above, with one exception: leaves were inoculated 2 days before the fungicide applications were made. All leaves were incubated in their petri plates $(100 \%$ relative humidity) at room temperature conditions $\left(21\right.$ to $23^{\circ} \mathrm{C}$, ambient lighting) and organized in a completely randomized design for the duration of the experiment. Seven days after inoculation, disease was assessed on individual leaves using a 0 -to- 5 scale, where $0=$ no disease, $1=1$ to $11 \%$ disease (midpoint $6 \%$ ), $2=12$ to $38 \%$ disease (midpoint $25 \%$ ), $3=39$ to $61 \%$ disease (midpoint $50 \%$ ), $4=62$ to $88 \%$ disease (midpoint $75 \%$ ), and $5=89$ to $100 \%$ disease (midpoint $95 \%$ ).

Fungicide evaluation on potted whole plants. All tomato plants (Brandywine Red) were grown in 9.5-cm-diameter pots in a growth chamber at $24^{\circ} \mathrm{C}$ with a 14 -h photoperiod and inoculated at 5 weeks. Plants were removed from the growth chamber for fungicide treatment and inoculation. The fungicide treatments were prepared as outlined for the detached-leaf experiments. Four plants for each treatment were arranged together and sprayed until runoff. The plants were then moved back to the growth chamber for several hours until foliage was dry. Inoculum for the US-23 isolate of $P$. infestans was produced as outlined above and adjusted to 10,000 sporangia/ml. Each plant was uniformly sprayed with $40 \mathrm{ml}$ of inoculum until the total volume of suspension was exhausted. Plants were immediately individually covered with clear plastic bags for $24 \mathrm{~h}$ and arranged in a randomized complete block design under fluorescent lighting. Plants were maintained under ambient laboratory conditions (temperature 21 to $23^{\circ} \mathrm{C}$ ) with a 14-h photoperiod. The growth chamber was loosely covered with clear plastic to promote humid conditions for disease development. The plants were misted daily with distilled water using a clean Solo sprayer and watered every other day. Disease ratings were assigned to all leaves of individual plants using the same scale as for the detached leaves at 7 days after inoculation. 
Data analysis. The detached-leaf experiments were performed two times for each of the three $P$. infestans isolates, and each isolate was tested at the same time. The potted whole-plant experiment was performed two times with the US-23 isolate only. This choice was made because the late blight pathogen populations in Wisconsin, as in much of the rest of the United States, were predominated by US-23 during the years of this experiment (2010 to 2012) and we felt that results would be most relevant to current disease conditions. The 0 -to-5 disease ratings were converted to their corresponding midpoint percentages, the data were analyzed using analysis of variance, and Tukey tests $(P=0.05)$ were used to determine significant differences between treatments and between isolates within each experiment (SAS Institute Inc., Cary, NC).

\section{Results}

Detached-tomato-leaflet assays provided an efficient method of testing multiple fungicides for preventative and postinoculation control of a single pathogen cycle of late blight caused by three different clonal lineages of $P$. infestans. Leaflets remained green and turgid throughout the duration of the experiments.

Late blight caused by US-22, US-23, and US-24 isolates on detached tomato leaflets was significantly reduced compared with the inoculated control with Bravo Ultrex, Ridomil Gold SL, Revus, Zonix, and the low and high rates of EF400 when applied preventatively (prior to pathogen inoculation) (Table 2). Additionally, late blight caused by the US-22 and US-23 isolates was significantly controlled with preventative application of Phostrol, and late blight caused by the US-23 isolate was significantly controlled with a low rate of Mycostat and a high rate of Champ (Table 2). Noninoculated controls resulted in no late blight with isolates of all late blight clonal lineages (Table 2). On whole potted tomato plants, Bravo Ultrex, Ridomil Gold SL, and the high rate of EF400 significantly reduced late blight caused by the US-23 isolate when applied preventatively, compared with the inoculated control (Table 2).

In the nonpreventative treatments (fungicides applied after pathogen inoculation), only Phostrol applied after inoculation with the US-22 $P$. infestans isolate and Bravo Ultrex applied after inoculation with the US-23 isolate provided significant control of late blight on detached tomato leaflets. All of the nonpreventative conventional fungicide treatments (Bravo Ultrex, Ridomil Gold SL, Revus, and Phostrol), Zonix, and EF400 were less effective in controlling late blight than when applied prior to pathogen inoculation. However, several of the biological treatments (Serenade ASO) and biopesticides (Regalia,
Oxidate, Mycostat) applied after pathogen inoculation resulted in numerically less disease with US-23 and US-24 isolates than did the applications of the same fungicides when applied preventatively.

Inoculated controls resulted in the highest late blight ratings with the US-23 isolate of $P$. infestans (100\% disease); US-22 resulted in the second highest disease ratings (approximately 84 to 94\%), and US-24 resulted in the lowest ratings (approximately 15 to $25 \%$ ). The US-24 $P$. infestans isolate always resulted in significantly lower disease ratings than the US-22 and US-23 isolates, except with the conventional fungicides Bravo Ultrex, Ridomil Gold SL, and Revus applied preventatively (Fig. 1A). When fungicides were applied after pathogen inoculation, the US-24 isolate resulted in significantly lower disease ratings than the US-22 and US-23 isolates (Fig. 1B). The US-22 and US-23 isolates resulted in statistically similar late blight when fungicides were applied preventatively in the cases of Zonix, baking soda, the low rate of Champ, Regalia, Serenade ASO, Oxidate, and the high rate of Mycostat. The US-22 and US-23 isolates resulted in statistically similar late blight when fungicides were applied after pathogen inoculation with most of the fungicide treatments, including Ridomil Gold SL, Revus, both rates of EF400, both rates of Mycostat, both rates of Champ, baking soda, Regalia, and Serenade ASO.

\section{Discussion}

Through detached-leaf assays and whole-potted-plant trials under controlled conditions, we demonstrated that several currently available conventional and noncopper organic fungicides, when applied preventatively, can limit a single infection cycle of late blight caused by isolates of the US-22, US-23, and US-24 clonal lineages. Application of fungicides is one of the primary means of controlling late blight during the production season on susceptible potato and tomato cultivars $(6,64)$. Effective fungicide choices are limited in organic production systems and few replicated efficacy data are available, especially for many noncopper fungicides. New clonal lineages of $P$. infestans continue to be identified in the United States, and it is important to determine efficacy of fungicides against the current genetically distinct population. We have shown that the US-24 clonal lineage resulted in significantly less late blight on detached leaflets of Brandywine Red tomato than the US-22 or US-23 lineage.

Of the biopesticides tested in this study, EF400 and Zonix provided the best late blight control caused by US-22, US-23, and US-24 $P$. infestans clonal lineages on detached tomato leaflets when applied preventatively. The high rate of EF400 also significantly

Table 1. Fungicide treatments, manufacturers, active ingredients, and label rates tested for efficacy against the isolates of US-22, US-23, and US-24 clonal lineages of Phytophthora infestans on 'Brandywine Red' tomato

\begin{tabular}{|c|c|c|c|c|}
\hline Treatment & Manufacturer & Active ingredient & Label rates ${ }^{y}$ & Rate for $100 \mathrm{ml}$ of water \\
\hline Inoculated control & NA & NA & NA & NA \\
\hline Noninoculated & NA & NA & NA & NA \\
\hline Baking soda & Arm \& Hammer, Princeton, NJ & Sodium bicarbonate & $1 \mathrm{Tbs} / \mathrm{gal}$ water & $0.5 \mathrm{tsp}$ in $630 \mathrm{ml}$ \\
\hline Bravo Ultrex & Syngenta Crop Protection, Greensboro, NC & Chlorothalonil & $1.8 \mathrm{lb} / \mathrm{acre}$ & $0.019 \mathrm{~g}$ \\
\hline Champ Formula 2 & Nufarm Americas Inc., Burr Ridge, IL & Copper hydroxide & $1.33 \mathrm{pt} / \mathrm{acre}$ & $0.014 \mathrm{ml}$ \\
\hline Champ Formula 2 & Nufarm Americas Inc., Burr Ridge, IL & Copper hydroxide & $2 \mathrm{pt} / \mathrm{acre}$ & $0.022 \mathrm{ml}$ \\
\hline EF400 & USAgritech, Inc. Paso Robles, CA & Herbal extract mixture & $4 \mathrm{pt} / 100 \mathrm{gal}$ of water & $0.49 \mathrm{ml}$ \\
\hline EF400 & USAgritech, Inc. Paso Robles, CA & Herbal extract mixture & $6 \mathrm{pt} / 100 \mathrm{gal}$ of water & $0.75 \mathrm{ml}$ \\
\hline Mycostat & Diacon Technologies Ltd., Richmond BC & Oil extract & $0.5 \mathrm{pt} / \mathrm{acre}$ & $0.006 \mathrm{ml}$ \\
\hline Mycostat & Diacon Technologies Ltd., Richmond BC & Oil extract & $1 \mathrm{pt} / \mathrm{acre}$ & $0.011 \mathrm{ml}$ \\
\hline OxiDate & BioSafe Systems LLC, East Hartford, CT & Hydrogen dioxide & $1 \mathrm{gal} / 100 \mathrm{gal}$ of water & $1 \mathrm{ml}$ in $99 \mathrm{ml}$ of water \\
\hline Phostrol & NuFarm Americas Inc., Burr Ridge, IL & Phosphorous acids & $10 \mathrm{pt} / \mathrm{acre}$ & $0.11 \mathrm{ml}$ \\
\hline Regalia & Marrone Bio Innovations, Davis, CA & Reynoutria sachalinensis extract & $2 \mathrm{pt} / \mathrm{acre}$ & $0.022 \mathrm{ml}$ \\
\hline Revus & Syngenta Crop Protection, Greensboro, NC & Mandipropamid & $0.5 \mathrm{pt} / \mathrm{acre}$ & $0.006 \mathrm{ml}$ \\
\hline Ridomil Gold SL & Syngenta Crop Protection, Greensboro, NC & Mefenoxam & $1 \mathrm{pt} / \mathrm{acre}$ & $0.011 \mathrm{ml}$ \\
\hline Serenade ASO & AgraQuest, Inc. Davis, CA & Bacillus subtilis QST 713 & $12.0 \mathrm{pt} / \mathrm{acre}$ & $0.130 \mathrm{ml}$ \\
\hline Zonix & Jeneil Biosurfactant Co., Saukville, WI & Rhamnolipid biosurfactant & $100 \mathrm{ppm}$ & $1 \mathrm{ml}$ in $99 \mathrm{ml}$ of water \\
\hline
\end{tabular}

y Rates chosen were common recommended rates and units of measurements on each label. Both a high and a low recommended rate were used in some cases. Abbreviations: $\mathrm{NA}=$ not applicable, $\mathrm{ppm}=$ parts per million, $\mathrm{pt}=$ pint, $\mathrm{Tbs}=$ tablespoon, $\mathrm{tsp}=$ teaspoon, and gal $=\mathrm{gallon}$.

${ }^{\mathrm{z}}$ Recommended label rates were converted to the amount needed in $100 \mathrm{ml}$ of water and applied until runoff. Where fungicide label rates were provided in quantity per acre, we converted to quantity per square feet, which represented the total area of excised leaflets to be treated per fungicide replication. Label rates given in ppm or per volume of water were converted to equivalent proportions per $100 \mathrm{ml}$ of total spray volume. 
controlled late blight caused by the US-23 clonal lineage in the whole-potted-plant experiment. The active ingredients for EF400 are clove, peppermint, and rosemary oil. The mode of action of these essential oils is unclear but they are recognized as antifungal compounds (17). Trials in Michigan with the US-22 lineage on potato suggest that EF400 is effective against late blight in a field setting with polycyclic late blight pressure (56). Zonix is a rhamnolipid biosurfactant that alters the osmotic potential of zoospore membranes, resulting in cell rupture and death (69). In laboratory microscope evaluations, a drop of Zonix applied to a zoospore suspension immediately eliminated all swimming zoospores (data not shown). Zoospores are released by $P$. infestans at lower temperatures ( 8 to $18^{\circ} \mathrm{C}$ ) when free water exits but, at higher temperatures, sporangia germinate directly (65). Our inoculations and incubations were performed at 21 to $23^{\circ} \mathrm{C}$, higher than the optimal temperature for indirect germination of sporangia into zoospores, but Zonix was still effective. This would suggest that the isolates of $P$. infestans that we tested may have a low rate of effective direct sporangial germination. A low rate of direct germination at 20 and $25^{\circ} \mathrm{C}$ has been observed for other isolates of the US-22, US-23, and US-24 lineages (11). Further whole-plant greenhouse or field trials where disease development is similar to what would occur in a commercial crop are needed to further confirm the efficacy of EF400 and Zonix but our results suggest that the two biopesticides may be effective in a late blight management program.

It is uncertain why the copper treatments (Champ) performed so poorly against late blight caused by isolates of the US-22, US-23, and US-24 clonal lineages in our experiments. Fungicide formulations containing copper have a long history of being the most effective organic fungicides available $(15,61,62)$. Anecdotal reports from Wisconsin commercial organic fields do indicate successful late blight management with copper fungicides when applied preventatively and repeatedly in recent years (2010 to 2013). Our experiments were replicated with statistically similar results for the coppercontaining treatments in both detached-leaf and whole-plant assays and, each time, the copper formulation performed statistically worse than some of the biopesticides. Although copper tolerance in fungi has been documented, resistance in oomycete plant pathogens has not been previously reported (16). The potential for copper tolerance in new clonal lineages of $P$. infestans requires further investigation.

Mycostat, like EF400, is an oil blend, but Mycostat did not significantly control late blight caused by the US-22, US-23, or US-24 isolates when applied at either the low or high rate after pathogen inoculation. As a preventive treatment, a low rate of Mycostat did significantly reduce late blight caused by the US-23 isolate. It is not clear why the high rate of Mycostat did not perform as well as or statistically similarly to the lower rate when applied preventatively. In postinoculation applications, both rates of Mycostat performed poorly (and not significantly different) in control of late blight caused by US-22, US-23, and US-24 isolates. Baking soda and OxiDate also provided ineffective control in both the preventative and postinoculation experiments across all of the late blight clonal lineages. Although these two fungicides lack residual protectant activity, they can reportedly kill sporangia on contact and may play a role in an overall late blight management program by reducing inoculum and, subsequently, spread of disease (3).

Regalia and Serenade ASO biopesticides were ineffective in controlling late blight caused by $P$. infestans isolates belonging to the US-22, US-23, and US-24 clonal lineages in our single disease cycle detached-tomato-leaflet assays. The active ingredient in Regalia is an extract from giant knotweed (Reynoutria sachalinensis) that enhances plant defenses by inducing systemic resistance in treated plant tissues (20). Regalia did not provide significant control of late blight caused by any of the pathogen clonal lineages in the preventative or postinoculation detached-tomato-leaflet assays. This lack of efficacy may have been the result of our short-duration evaluation process, and detached leaflets may not respond in the same manner as whole plants in the process of inducing disease resistance. Serenade ASO, containing the Bacillus subtilis QST713 bacteria, resulted in levels of late blight statistically similar to those in the untreated,

Table 2. Mean disease ratings of fungicide treatments applied against the isolates of US-22, US-23, and US-24 clonal lineages of Phytophthora infestans on Brandywine Red tomato at 7 days postinoculation ${ }^{\mathrm{v}}$

\begin{tabular}{|c|c|c|c|c|c|c|c|}
\hline \multirow[b]{4}{*}{ Treatment $^{\mathrm{z}}$} & \multicolumn{7}{|c|}{ Mean disease severity ( $\%$ disease) } \\
\hline & \multicolumn{6}{|c|}{ Detached leaves } & \multirow{3}{*}{$\frac{\text { Potted plants }^{\natural}}{\text { Preventative }^{\text {US-23 }}}$} \\
\hline & \multicolumn{3}{|c|}{ Preventative $^{x}$} & \multicolumn{3}{|c|}{ Nonpreventative $\mathrm{y}^{\mathrm{y}}$} & \\
\hline & US-22 & US-23 & US-24 & US-22 & US-23 & US-24 & \\
\hline Inoculated control & $93.8 \mathrm{c}$ & $100 \mathrm{e}$ & 24.7 cde & $84.4 \mathrm{~cd}$ & $100 \mathrm{c}$ & $15.3 \mathrm{a}$ & $90.6 \mathrm{c}$ \\
\hline Noninoculated & $0 \mathrm{a}$ & $0 \mathrm{a}$ & $0 \mathrm{a}$ & $0 \mathrm{a}$ & $0 \mathrm{a}$ & $0 \mathrm{a}$ & $0 \mathrm{a}$ \\
\hline Bravo Ultrex & $0 \mathrm{a}$ & $0.3 \mathrm{a}$ & $0 \mathrm{a}$ & $87.5 \mathrm{~cd}$ & $68.8 \mathrm{~b}$ & $8.1 \mathrm{a}$ & $9.4 \mathrm{a}$ \\
\hline Ridomil Gold SL & $0.3 \mathrm{a}$ & $0 \mathrm{a}$ & $0 \mathrm{a}$ & $68.8 \mathrm{bc}$ & $78.8 \mathrm{bc}$ & $11.3 \mathrm{a}$ & $2.5 \mathrm{a}$ \\
\hline Revus & $1.6 \mathrm{a}$ & $0.3 \mathrm{a}$ & $0 \mathrm{a}$ & $75 \mathrm{bcd}$ & $82.8 \mathrm{bc}$ & $10.3 \mathrm{a}$ & NA \\
\hline Zonix & $12.8 \mathrm{a}$ & $22.2 \mathrm{~b}$ & $1.6 \mathrm{a}$ & $84.4 \mathrm{~cd}$ & $100 \mathrm{c}$ & $13.8 \mathrm{a}$ & $68.8 \mathrm{bc}$ \\
\hline EF400 low & $39.1 \mathrm{~b}$ & $20.0 \mathrm{ab}$ & $1.3 \mathrm{a}$ & $85.9 \mathrm{~cd}$ & $98.4 \mathrm{c}$ & $17.5 \mathrm{a}$ & $71.9 \mathrm{bc}$ \\
\hline EF400 high & $44.4 \mathrm{~b}$ & $24.4 \mathrm{~b}$ & $2.2 \mathrm{ab}$ & $92.2 \mathrm{~d}$ & $100 \mathrm{c}$ & $15.9 \mathrm{a}$ & $59.4 \mathrm{~b}$ \\
\hline Phostrol & $50.9 \mathrm{~b}$ & $24.4 \mathrm{~b}$ & $3.8 \mathrm{abc}$ & $58.4 \mathrm{~b}$ & $90.6 \mathrm{c}$ & $4.7 \mathrm{a}$ & $78.1 \mathrm{bc}$ \\
\hline Mycostat low & $100 \mathrm{c}$ & $51.6 \mathrm{c}$ & 26.6 abcde & $93.8 \mathrm{~d}$ & $98.4 \mathrm{c}$ & $14.4 \mathrm{a}$ & NA \\
\hline Champ high & $95.3 \mathrm{c}$ & $75.0 \mathrm{~d}$ & $10.3 \mathrm{abcd}$ & $90.6 \mathrm{~d}$ & $98.4 \mathrm{c}$ & $12.2 \mathrm{a}$ & $87.5 \mathrm{bc}$ \\
\hline Baking Soda & $89.1 \mathrm{c}$ & $84.4 \mathrm{de}$ & 19.1 abcde & $93.8 \mathrm{~d}$ & $98.4 \mathrm{c}$ & $13.1 \mathrm{a}$ & NA \\
\hline Champ low & $92.2 \mathrm{c}$ & $84.4 \mathrm{de}$ & 8.8 abcd & $87.5 \mathrm{~cd}$ & $100 \mathrm{c}$ & $11.6 \mathrm{a}$ & $81.3 \mathrm{bc}$ \\
\hline Regalia & $98.4 \mathrm{c}$ & $87.5 \mathrm{de}$ & 23.4 bcde & $90.6 \mathrm{~d}$ & $96.9 \mathrm{c}$ & $11.6 \mathrm{a}$ & NA \\
\hline Serenade Soil & $100 \mathrm{c}$ & $92.9 \mathrm{de}$ & $26.6 \mathrm{de}$ & $93.8 \mathrm{~d}$ & $96.9 \mathrm{c}$ & $11.3 \mathrm{a}$ & NA \\
\hline Oxidate & $100 \mathrm{c}$ & $93.8 \mathrm{de}$ & $10.0 \mathrm{abcd}$ & $84.4 \mathrm{~cd}$ & $100 \mathrm{c}$ & $11.6 \mathrm{a}$ & NA \\
\hline Mycostat high & $100 \mathrm{c}$ & $95.3 \mathrm{de}$ & $33.4 \mathrm{e}$ & $89.1 \mathrm{~cd}$ & $98.4 \mathrm{c}$ & $13.4 \mathrm{a}$ & NA \\
\hline
\end{tabular}

${ }^{v}$ Means for each treatment within a row (clonal lineage) followed by same letters are not statistically different (Tukey's Test, $P=0.05$ ). Disease ratings were taken

7 days after inoculation. Disease was assessed on individual leaves using a 0 -to- 5 scale, where $0=$ no disease, $1=1$ to $11 \%$ disease (midpoint $6 \%$ ), $2=12$ to $38 \%$ disease (midpoint 25\%), $3=39$ to $61 \%$ disease (midpoint 50\%), $4=62$ to $88 \%$ disease (midpoint $75 \%$ ), and $5=89$ to $100 \%$ disease (midpoint $95 \%$ ). NA = not applicable.

${ }^{\text {w }}$ Five-week-old potted tomato plants were sprayed with fungicides and allowed to dry before inoculation with $P$. infestans.

${ }^{\mathrm{x}}$ Fungicides were applied to detached tomato leaflets and allowed to fully dry (approximately $1 \mathrm{~h}$ ) prior to inoculation with $P$. infestans at $2 \mathrm{~h}$ after fungicide treatment.

${ }^{y}$ Fully expanded detached tomato leaflets were inoculated with $P$. infestans 2 days before applying each fungicide treatment.

z Designation "high" or "low" refers to either the higher or lower rate of each fungicide. 
inoculated controls with clonal lineages US-22, US-23, and US-24. Serenade ASO is active as a fungicide in multiple manners, including inducing systemic resistance to disease within the plant, producing complex lipopeptides which directly impact sporulation and pathogen mycelia, and colonizing plant parts to out complete the plant pathogens (35). Biopesticides and biological products often require specialized timing and methods of application to best utilize their activity as fungicides $(17,54)$. This study focuses on efficacy in response to a single inoculation event and may not be ideal for appropriately testing all biopesticide and biological products. Further experiments with designs specific to fungicide mode of action are necessary to appropriately understand the potential role of these unique fungicides.

The effectiveness of the conventional fungicides Bravo Ultrex (chlorothalonil), Ridomil Gold SL (mefenoxam), Revus (mandipropamid), and Phostrol (active ingredient monoand di-basic salts of phosphorous acids) in our preventative detached-leaflet assay indicated that fungicide resistance was not evident among the $P$. infestans clonal lineages tested. Although it is unlikely that resistance to chlorothalonil or salts of phosphorous acids will develop within the $P$. infestans population due to their broad-spectrum, multisite activity, greater risk exists with mandipropamid, even though field resistance has yet to be detected for $P$. infestans and research has indicated that the likelihood of resistance development is low $(8,10)$. In in vitro tests, isolates of the US-24 lineage have tested partially or fully insensitive to mefenoxam (55) but the mefenoxam (Ridomil Gold SL) treatment was effective against the US-24 isolate on tomato leaves in our work.

Although Phostrol is sometimes considered a biopesticide, it does not technically fit into this category based on the Environmental Protection Agency's (EPA) definition. The EPA defines a biopesticide as a naturally occurring substance that fall into one of three categories: (i) microbial pesticides consisting of microorganisms, (ii) plant incorporate protectants (PIPs) or substances that plants produce from genetic material that has been added to the plant (i.e., Bacillus thuringiensis or BT), and (iii) biochemical pesticides that are naturally occurring substances that control pests by nontoxic means. Phosphorous acid salts, including Phostrol, are not naturally occurring because they require a synthetic process to manufacture. Phostrol and other fungicides in this group are conventional fungicides but generally are considered less toxic than some of the other available fungicides, such as chlorothalonil. This characteristic, combined with demonstrated contact efficacy and induction of potato tuber resistance, make this fungicide a good choice in conventional systems for late blight control $(8,67)$.

Biopesticides that alone do not perform as well as conventional fungicides may have a useful role in fungicide resistance management. Due to their multisite activity, biopesticides have a very low risk for development of resistance. Tank mixing or alternating biopesticides with conventional fungicides may help reduce the environmental impact of late blight programs as well as lengthen the useful life of medium- to high-risk conventional fungicides.

In both the preventative and postinoculation detached-leaflet experiments, late blight caused by the isolate representing the US-24 clonal lineage resulted in significantly less disease than US-22 or US-23. The US-24 clonal lineage has been infrequently isolated from tomato since it was first identified in the United States $(11,38,55)$. Additionally, numerous laboratory experiments have shown that infection and disease progression (58), including sporulation $(11,57)$, are limited with the US-24 clonal lineage on tomato when compared with US-22 and US-23 clonal lineages. The reduced virulence, as seen in our work (reduction of approximately 15 to $25 \%$ compared with US-23), and pathogen sporulation, as noted in previous work, suggests that late blight caused by isolates of the US-24 clonal lineage may require less intensive late blight management than disease caused by US-22 or US-23 isolates $(11,57)$.

The contrast between the efficacy of the fungicides applied before inoculation compared with after inoculation was striking. Two days after inoculation, when the fungicides were applied, no sign or symptom of disease was observed. However, the leaves were latently infected with $P$. infestans in its biotrophic phase (18). The established infection was not effectively controlled with postinoculation fungicide treatments. This is important to consider for management, because our results indicate that many of the fungicides tested must be applied prior to the onset of disease to be effective, and infected leaves may show no sign of disease for several days. Disease forecasting models can predict when environmental conditions are most

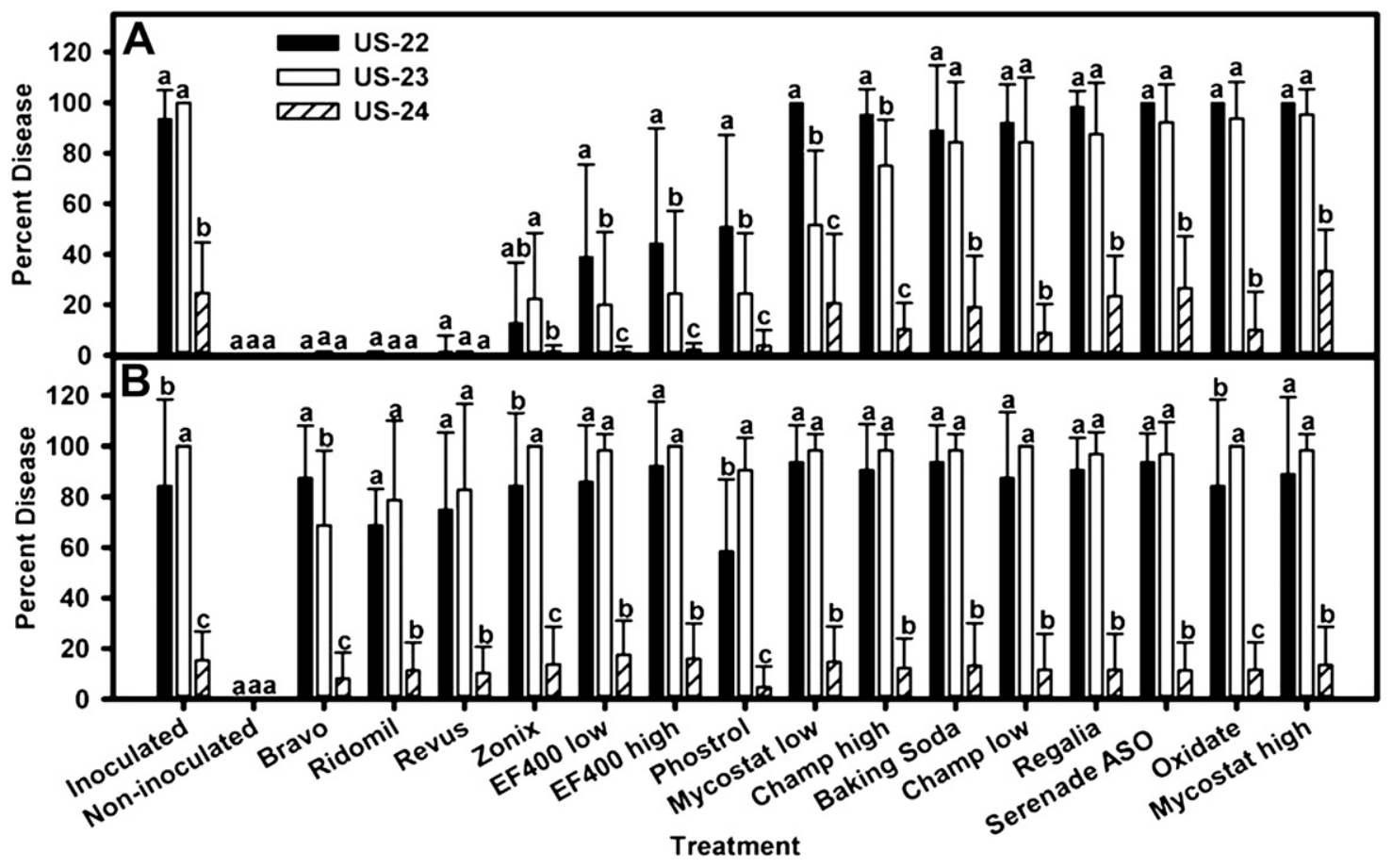

Fig. 1. Efficacy of fungicides applied A, preventatively or B, 2 days after inoculation with the US-22, US-23, and US-24 isolates of Phytophthora infestans on detached Brandywine Red tomato leaflets. Late blight disease ratings were taken 7 days after inoculation. Letters over bars indicate significant differences between the three isolates for each treatment (Tukey's Test, $P=0.05)$. "High" or "low" refers to the higher and lower rates of each fungicide, respectively. 
conducive to late blight infection and recommend the application of fungicides $(44,64)$. Our results underscore the utility of these forecasting systems for adequately controlling late blight.

Our experiments were performed on tomato foliage under controlled conditions but the fungicides tested are also approved for use on potato late blight and similar efficacies may be extrapolated. The exception would be with results from the US-24 clonal lineage, because this lineage has low virulence on tomato but is virulent on potato $(38,55)$. Field trials with polycyclic late blight pressure are necessary to further evaluate the control potential of nonconventional fungicides on potato and tomato under field conditions.

Late blight can be a challenging disease to manage, particularly in an organic production system. We have demonstrated that several noncopper fungicide formulations are effective in controlling this potentially devastating disease when applied prophylactically on detached leaflets of susceptible Brandywine Red tomato in a single disease cycle. With concerns over copper build up in soil and unsightly copper residues on organic produce, our results showing efficacy of noncopper formulations may be particularly timely to advance research to open field trials and, ultimately, to support effective recommendations for fungicide selection in organic and conventional systems.

\section{Acknowledgments}

This work was supported, in part, by Hatch Formula Funds granted to A. J. Gevens at the University of Wisconsin-Madison and a Wisconsin Potato Industry Board-Wisconsin Distinguished Graduate Fellowship. We thank K. Cleveland, A. Pfeil, A. Mitchell, S. Donovan, L. Thomas, and A. Turner for technical assistance in the University of Wisconsin Potato and Vegetable Pathology Laboratory.

\section{Literature Cited}

1. Anonymous. 2010. USABlight: A National Project on Tomato and Potato Late Blight in the United States. www.usablight.org.

2. AVRDC. 1994. Pages 201-203 in: 1993 Progress Report. Asian Vegetable Research and Development Center, Shanhua, Tainan, Taiwan.

3. Baldry, M. G. 1983. The bactericidal, fungicidal, and sporicidal properties of hydrogen peroxide and peracetic acid. J. Appl. Bacteriol. 54:417-423.

4. Besnard, E., Chenu, C., and Robert, M. 2001. Influence of organic amendments on copper distribution among particle-size and density fractions in Champagne vineyard soils. Environ. Pollut. 112:329-337.

5. Bonde, R., and Schultz, E. S. 1943. Potato cull piles as a source of late blight infection. Am. Potato J. 20:112-118.

6. Bussan, A. J., Colquhoun, J. B., Cullen, E. M., Davis, V. M., Gevens, A. J., Groves, R. L., Heider, D. J., Nice, G. R. W., and Ruark, M. D. 2012. Commercial Vegetable Production in Wisconsin-2013. University of Wisconsin Cooperative Extension, Madison, WI.

7. Caten, C. E., and Jinks, J. L. 1968. Spontaneous variability of a single isolate of Phytophthora infestans. I. Cultural variation. Can. J. Bot. 46:329-348.

8. Cohen, Y., and Coffey, M. D. 1986. Systemic fungicides and the control of oomycetes. Annu. Rev. Phytopathol. 24:311-338.

9. Cohen, Y., Reuveni, M., and Eyal, H. 1979. The systemic antifungal activity of Ridomil against Phytophthora infestans on tomato plants. Phytopathology 69:645-649.

10. Cohen, Y., Rubin, E., Hadad, T., Gotlieb, D., Sierotzki, H., and Gisi, U. 2007. Sensitivity of Phytophthora infestans to mandipropamid and the effect of enforced selection pressure in the field. Plant Pathol. 56:836-842.

11. Danies, G., Small, I. M., Myers, K., Childers, R. A., and Fry, W. E. 2013. Phenotypic characterization of recent clonal lineages of Phytophthora infestans in the United States. Plant Dis. 97:873-881.

12. Deahl, K. L., DeMuth, S. P., Sinden, S. L., and Rivera-Peña, A. 1995. Identification of mating types and metalaxyl resistance in North American populations of Phytophthora infestans. Am. Potato J. 72:35-49.

13. Deahl, K. L., Inglis, D. A., and DeMuth, S. P. 1993. Testing for resistance to metalaxyl in Phytophthora infestans isolates in northwestern Washingon. Am. Potato J. 70:779-795.

14. Deluisa, A., Giadnon, P., Aichner, M., Bortolami, P., Bruna, L., Lupetti, A., Nardelli, F., and Stringari, G. 1996. Copper pollution in Italian vinyard soils. Commun. Soil Sci. Plant Anal. 27:1537-1548.

15. Dorn, B., Musa, T., Krebs, H., Fried, P. M., and Forrer, H. R. 2007. Control of late blight in organic potato production: evaluation of copper-free preparations under field, growth chamber, and laboratory conditions. Eur. J. Plant Pathol. 119:217-240.

16. Du, A., Cao, L., Zhang, R., and Pan, R. 2009. Effects of a copper-resistant fungus on copper adsorption and chemical forms in soils. Water Air Soil Pollut. 201: 99-107.

17. El-Zemity, S. R., and Ahmed, S. M. 2005. Antifungal activity of some essential oils and their major chemical constituents against some phytopathogenic fungi. J. Pest Control Environ. Sci. 13:61-72.
18. Erwin, D. C., and Ribeiro, O. K. 1996. Phytophthora Diseases Worldwide. American Phytopathological Society, St. Paul, MN.

19. Flores-Vélez, L. M., Ducaroir, J., Jaunet, A. M., and Robert, M. 1996. Study of the distribution of copper in an acid sandy vinyard soil by three different methods. Eur. J. Soil Sci. 47:523-532.

20. FRAC. 2015. Code list. www.frac.info/publications/downloads.

21. Fry, W. E. 2008. Phytophthora infestans: the plant (and $R$ gene) destroyer. Mol. Plant Pathol. 9:385-402.

22. Fry, W. E., and Goodwin, S. B. 1997. Re-emergence of potato and tomato late blight in the United States. Plant Dis. 81:1349-1357.

23. Gevens, A. J., Seidl, A. C., Clark, R., and Sanchez-Perez, A. 2011. Late blight management with new Phytophthora infestans genotypes. Pages 1-4 in: Wisc. Annu. Potato Meet. University of Wisconsin-Madison, College of Agriculture and Life Sciences, Research Division, Stevens Point.

24. Goodwin, S. B., Cohen, B. A., Deahl, K. L., and Fry, W. E. 1994. Migration from northern Mexico as the probable cause of recent genetic changes in the populations of Phytophthora infestans in the United States and Canada. Phytopathology 84:553-558.

25. Goodwin, S. B., Cohen, B. A., and Fry, W. E. 1994. Panglobal distribution of a single clonal lineage of the Irish potato famine fungus. Proc. Natl. Acad. Sci. USA 91:11591-11595.

26. Goodwin, S. B., Drenth, A., and Fry, W. E. 1992. Cloning and genetic analyses of two highly polymorphic, moderately repetitive nuclear DNAs from Phytophthora infestans. Curr. Genet. 22:107-115.

27. Goodwin, S. B., Fry, W. E., and Schneider, R. E. 1995. Use of celluloseacetate electrophoresis for rapid identification of allozyme genotypes of Phytophthora infestans. Plant Dis. 79:1181-1185.

28. Goodwin, S. B., Smart, C. D., Sandrock, R. W., Deahl, K. L., Punja, Z. K., and Fry, W. E. 1998. Genetic change within populations of Phytophthora infestans in the United States and Canada during 1994 to 1996: Role of migration and recombination. Phytopathology 88:939-949.

29. Goodwin, S. B., Sujkowski, L. S., Dyer, A. T., Fry, B. A., and Fry, W. E. 1995 Direct detection of gene flow and probable sexual reproduction of Phytophthora infestans in northern North America. Phytopathology 85: 473-479.

30. Goodwin, S. B., Sujkowski, L. S., and Fry, W. E. 1995. Rapid evolution of pathogenicity within clonal lineages of the potato late blight disease fungus. Phytopathology 85:669-676.

31. Goth, R. W. 1981. An efficient technique for prolonged storage of Phytophthora infestans. Am. Potato J. 58:257-260.

32. Groves, C. L. 2002. Characterization of Phytophthora infestans from Maine during 1999 and 2000. Am. J. Potato Res. 79:325-333.

33. Grünwald, N. J., Sturbaum, A. K., Montes, G. R., Serrano, E. G., LozoyaSaldaña, H., and Fry, W. E. 2006. Selection for fungicide resistance within a growing season in field populations of Phytophthora infestans at the center of origin. Phytopathology 96:1397-1403.

34. Guenthner, J. F., Michael, K. C., and Nolte, P. 2001. The economic impact of potato late blight on US growers. Potato Res. 44:121-125.

35. Harman, G. E., Obregon, M. A., Samuels, G. J., and Lorito, M. 2010 Changing models for commercialization and implementation of biocontrol in the developing and developed world. Plant Dis. 94:928-030.

36. Haverkort, A. J., Boonekamp, P. M., Hutten, R., Jacobsen, E., Lotz, L. A. P., Kessel, G. J. T., Visser, R. G. F., and van der Vossen, E. A. G. 2008. Societal costs of late blight in potato and prospects of durable resistance through cisgenic modification. Potato Res. 51:47-57.

37. Hodgson, W. A., and Grainger, P. N. 1964. Culture of Phytophthora infestans on artificial media prepared from rye seeds. Can. J. Plant Sci. 44:583.

38. Hu, C.-H., Perez, F. G., Donahoo, R. S., McLeod, A., Myers, K., Ivors, K. Secor, G., Roberts, P. D., Deahl, K. L., Fry, W. E., and Ristaino, J. B. 2012. Recent genotypes of Phytophthora infestans in the eastern United States reveal clonal populations and reappearance of mefenoxam sensitivity. Plant Dis. 96:1323-1330.

39. Johnson, D. A., and Cummings, T. F. 2013. A plant stem inoculation assay for assessing transmission of Phytopthora infestans from potato seed tubers to emerged shoots. Plant Dis. 97:183-188.

40. Kadish, D., and Cohen, Y. 1988. Fitness of Phytophthora infestans isolates from metalaxyl-sensitive and -resistant populations. Phytopathology 78:912915.

41. Kalischuk, M., Al-Mughrabi, K. I., Peters, R. D., Howard, R. J., Platt, H. W., and Kawchuk, L. M. 2012. Genetic composition of Phytophthora infestans in Canada reveals migration and increased diversity. Plant Dis. 96:1729-1735.

42. Kato, M., Mizubuti, E. S., Goodwin, S. B., and Fry, W. E. 1997. Sensitivity to protectant fungicides and pathogenic fitness of clonal lineages of Phytophthora infestans in the United States. Phytopathology 87:973-978.

43. Kim, M.-J., and Mutschler, M. A. 2006. Characterization of Late Bligh Resistance Derived from Solanum pimpinellifolium L3708 against Multiple Isolates of the Pathogen Phytophthora infestans. J. Am. Soc. Hortic. Sci. 131:637-645.

44. Krause, R. A., Massie, L. B., and Hyre, R. A. 1975. BLITECAST, a computerized forecast of potato late blight. Plant Dis. Rep. 59:95-98.

45. Lamour, K. H., and Hausbeck, M. K. 2001. Investigating the spaciotemporal genetic structure of Phytophthora capsici in Michigan. Phytopathology 91 973-980. 
46. Legard, D. E., Lee, T. Y., and Fry, W. E. 1995. Pathogenic specialization in Phytophthora infestans: Aggressiveness on tomato. Phytopathology 85:13561361.

47. Malcolmson, J. F., and Black, W. 1966. New R genes in Solanum demissum Lindl. and their complementary races of Phytophthora infestans (Mont.) de Bary. Euphytica 15:199-203.

48. Marshall-Farrar, K., McGrath, M., James, R., and Stevenson, W. 1998. Characterization of Phytophthora infestans in Wisconsin from 1993 to 1995. Plant Dis. 82:434-436.

49. Mizubuti, E. S. G., and Fry, W. E. 1998. Temperature effects on developmental stages of isolates from three clonal lineages of Phytophthora infestans. Phytopathology 88:837-843.

50. Nowicki, M., Foolad, M. R., Nowakowska, M., and Kozik, E. 2012. Potato and tomato late blight caused by Phytophthora infestans: An overview of pathology and resistance breeding. Plant Dis. 96:4-17.

51. Olberholtzer, L., Dimitri, C., and Greene, C. 2005. Pages 1-22 in: Price Premiums Hold on as U.S. Organic Produce Market Expands. Electronic Outlook Report from the Economic Research Service. United States Department of Agriculture. http://www.ers.usda.gov/publications/vgs-vegetables-and-pulsesoutlook/vgs308-01.aspx

52. Punja, Z. K., Förster, H., Cunningham, I., and Coffey, M. D. 1998. Genotypes of the late blight pathogen (Phytophthora infestans) in British Columbia and other regions of Canada during 1993-1997. Can. J. Plant Pathol. 20:274-282.

53. Rademaker, M. 1998. Occupational contact dermatitis among New Zealand farmers. Australas. J. Dermatol. 39:164-167.

54. Rose, S., Parker, M., and Punja, Z. K. 2003. Efficacy of biological and chemical treatments for control of Fusarium root and stem rot on greenhouse cucumber. Plant Dis. 87:1462-1470.

55. Seidl, A. C., and Gevens, A. J. 2013. Characterization and distribution of three new clonal lineages of Phytophthora infestans causing late blight in Wisconsin from 2009 to 2012. Am. J. Potato Res. 90:551-560.

56. Seidl, A. C., Kirk, W. W., and Gevens, A. J. 2012. Efficacy of biopesticides for control of late blight caused by new clonal lineages of Phytophthora infestans in the Upper Midwest. Online publication. http://www.biopesticideindustryalliance.org/ newsfiles/file/2013\%20Fall/Efficacy\%20of\%20Biopesticides\%20-\%20Gevens\% 20131010.pdf

57. Seidl, A. C., Mitchell, A. J., Gevens, A. J. 2012. Assessing fitness of new Phytophthora infestans clonal lineages by comparing sporangial production on tomato leaves. (Abstr.) Phytopathology 102:S5.9.

58. Seidl Johnson, A. C., Jordan, S. A., and Gevens, A. J. 2014. Novel resistance in heirloom tomatoes and effectiveness of resistance in hybrids to Phytophthora infestans US-22, US-23, and US-24 clonal lineages. Plant Dis. 98:761-765.
59. Shattock, R. C. 1988. Studies on the inheritance of resistance to metalaxyl in Phytophthora infestans. Plant Pathol. 37:4-11.

60. Song, J.M., B. J., Naess, S. K., Raasch, J. A., Wieglus, S. M., Haberlach, G. T. Liu, J., Kuang, H., Austin-Phillips, S., Buell, C. R., Helgeson, J. P., Jiang, J. 2003. Gene $R B$ cloned from Solanum bulbocastanum confers broad spectrum resistance to potato late blight. Proc. Natl. Acad. Sci. USA 100: 9128-9133.

61. Speiser, B., Tamm, L., Amsler, T., Lambion, J., Bertrand, C., Hermansen, A., Rulssen, M. A., Haaland, P., Zarb, J., Santos, J., Shotton, P., Wilcockson, S. Jutharathep, P., Ghorbani, R., and Leifert, C. 2006. Improvement of late blight management in organic potato production systems in Europe: Field tests with more resistant potato varieties and copper based fungicides. Biol. Agric. Hortic. 23:393-412.

62. Stephan, D., Schmitt, A., Carvalho, M. S., Seddon, B., and Koch, E. 2005. Evaluation of biocontrol preparations and plant extracts for the control of Phytophthora infestans on potato leaves. Eur. J. Plant Pathol. 112:235-246.

63. Stevenson, W., James, R., Inglis, D., Johnson, D., Schotzko, R., and Thornton, R. 2007. Fungicide spray programs for Defender, a new potato cultivar with resistance to late blight and early blight. Plant Dis. 91:1327-1336.

64. Stevenson, W. R. 1983. An integrated program for managing potato late blight. Plant Dis. 67:1047-1048.

65. Stevenson, W. R., Loria, R., Franc, G. D., and Weingartner, D. P. 2001 Compendium of Potato Diseases. American Phytopathological Society, St. Paul, MN.

66. Stewart, H. E., Bradshaw, J. E., and Pande, B. 2003. The effect of the presence of R-genes for resistane to late blight (Phytophthora infestans) of potato (Solanum tuberosum) on the underlying level of field resistance. Plant Pathol. 52:193-198.

67. Taylor, R. J., Pasche, J. S., and Gudmestad, N. C. 2011. Effect of application method and rate on residual efficacy of mefenoxam and phosphorous acid fungicides in the control of pink rot of potato. Plant Dis. 95:997-1006.

68. Thurston, H. D. 1957. The culture of Phytophthora infestans. (Abstr.) Phytopathology 47:186.

69. United States Environmental Protection Agency. 2004. Biopesticides Registration Action Document: Rhamnolipid Biosurfactant (PC Code 110029). Office of Pesticide Programs Biopesticides and Pollution Prevention Division, Washington, DC. Online publication. http://www.epa.gov/opp00001/ chem_search/reg actions/registration/decision_PC-110029 11-May-04.pdf

70. Vleeshouwers, V. G. A. A., van Dooijeweert, W., Keizer, L. C. P., Kijpkes, L., Grovers, F., and Colon, L. T. 1999. A laboratory assay for Phytophthora infestans resistance in various Solanum species reflects the field situation. Eur. J. Plant Pathol. 105:241-250. 